\title{
Pregnancy complications among women born preterm
}

\author{
Ariane Boivin PhD, Zhong-Cheng Luo MD PhD, François Audibert MD, Benoit Mâsse PhD, \\ Francine Lefebvre MD, Réjean Tessier PhD, Anne Monique Nuyt MD
}

\begin{abstract}
Background: Adults who were born with low birth weights are at increased risk of cardiovascular and metabolic conditions, including pregnancy complications. Low birth weight can result from intrauterine growth restriction, preterm birth or both. We examined the relation between preterm birth and pregnancy complications later in life.
\end{abstract}

Methods: We conducted a population-based cohort study in the province of Quebec involving 7405 women born preterm $(554<32$ weeks, 6851 at 32-36 weeks) and a matched cohort of 16714 born at term between 1976 and 1995 who had a live birth or stillbirth between 1987 and 2008. The primary outcome measures were pregnancy complications (gestational diabetes, gestational hypertension, and preeclampsia or eclampsia).

Results: Overall, $19.9 \%$ of women born at less than 32 weeks, $13.2 \%$ born at 32-36 weeks and $11.7 \%$ born at term had at least 1 pregnancy complication at least once during the study period $(p<0.001)$. Women born small for gestational age (both term and preterm) had increased odds of having at least 1 pregnancy complication compared with women born at term and at appropriate weight for gestational age. After adjustment for various factors, including birth weight for gestational age, the odds of pregnancy complications associated with preterm birth was elevated by 1.95 -fold ( $95 \%$ confidence interval [Cl] 1.54-2.47) among women born before 32 weeks' gestation and 1.14 -fold $(95 \% \mathrm{Cl}$ 1.03-1.25) among those born at 32-36 weeks' gestation relative to women born at term.

Interpretation: Being born preterm, in addition to, and independent of, being small for gestational age, was associated with a significantly increased risk of later having pregnancy complications.
$\mathrm{N}$ umerous studies examining cohorts born mostly in the first half of the 20th century have emphasized the inverse relation between low birth weight and incidence later in life of cardiovascular and metabolic conditions, such as hypertension and type 2 diabetes. ${ }^{1}$ Epidemiologic studies seldom consider the effects of preterm birth and intrauterine growth restriction separately when studying the relation of these factors to low birth weight. Studies have suggested that adolescents and young adults born preterm have higher incidence of risk factors for metabolic (insulin resistance) and cardiovascular (higher blood pressure) dysfunctions..$^{2-4}$ With the increased survival of preterm newborns over the past 30 years, a substantially greater proportion of young adults are born before 37 or even 32 weeks' gestation and thus may represent a growing population at risk for conditions related to metabolic syndrome as they get older.

Pregnancy can be considered a stress test for future cardiovascular and metabolic health. Women with a history of gestational diabetes, gestational hypertension or preeclampsia are at increased risk of metabolic syndrome later in life. ${ }^{5-7}$ Furthermore, studies have shown that women born with low birth weights are at increased risk of gestational hypertension, preeclampsia and gestational diabetes..$^{8-10}$ However, many of these studies either have not taken into account gestational age or have a number of shortcomings, such as small sample, young population (mostly teenagers), degree of prematurity not specified or study population consisting mostly of late preterm births. ${ }^{611,12}$

In the province of Quebec, weight and gestational age have been recorded in a registry for all births since 1976, and data on all hospital-based diagnoses have been collected since 1987 . The aim of our study was to examine the relation between preterm birth and later pregnancy complications, independently of intrauterine growth restriction, among women born preterm in Quebec between 1976 and 1995 who delivered at least 1 newborn between 1987 and 2008. We also examined whether this association represents a dose-response relation, namely, whether the more prematurely born a woman is, the greater her risk of gestational diabetes, gestational hypertension, preeclampsia or eclampsia.
Competing interests: Benoit Mâsse has received consultancy fees from the International Partnership for Microbicides. No other competing interests were declared.

This article has been peer reviewed.

Correspondence to:

Anne Monique Nuyt, anne-monique.nuyt@ recherche-ste-justine.qc.ca

CMAJ 2012. DOI:10.1503/ cmaj.120143 


\section{Methods}

\section{Participants and study design}

This study was based on record linkage of administrative birth-related data files. In Quebec, as part of the universal health care system, all residents are registered with a unique health insurance identification number in Fichier d'inscription des personnes assurées (Health Insured Individuals database). This number allows linking of people to the different databases of the provincial health insurance program. Data matching was carried out at the Institut de la statistique du Québec (Quebec Institute of Statistics) following the protocol of the Environnement pour la promotion de la santé et du bien-être (Environment for the Promotion of Health and Welfare; www.epsebe.ca/diff/epsebe/web/faces /pages/promotion_sante_bien_etre.jspx). This protocol, managed by the Quebec Institute of Statistics, is a temporary data repository providing remote access to authorized researchers.

In our study, the linking of 3 databases was required: Registre des événements démographiques (Demographic Events Registry), the Health Insured Individuals database, and the Maintenance et exploitation des données pour l'étude de la clientèle hospitalière (Maintenance and Data Processing for the Study of the Hospital Clientele; known in Quebec as "Med-Écho") database. The Demographic Events Registry comprises information about all live births, stillbirths, marriages and deaths in the province. The Med-Écho database includes information about all hospital-based diagnoses and interventions. In Quebec, almost all deliveries occur in hospitals $\left(99.8 \%\right.$ in $\left.2005^{13}\right)$. All pairing and data linkage were realized using probabilistic linkage methods ${ }^{14}$ and the specific software (Generalized Record Linkage System, version 4.4.02 $2^{15}$ ) developed by Statistics Canada.

We used an exposed (born preterm) versus unexposed (born term) design. The exposed cohort comprised women born preterm between 1976 and 1995 in Quebec. Women born before 23 weeks' gestation and those born to multiplebirth $(\geq 3)$ pregnancies were excluded. With a frequency matching of $1: 2$, a cohort of unexposed women (i.e., born at term at 37-42 weeks' gestation; $\geq 43$ weeks excluded) was formed according to year of birth and singleton versus twin status. Women born at term were selected by the Quebec Institute of Statistics by random sampling using SAS software version 9.4. The women were followed prospectively by linking data from the Demographic Events Registry to data from the Health Insured Individuals databases to identify those who had at least 1 live birth or stillbirth between 1987 and 2008. The year 1976 represents the first year for which reliable data for gestational age were available in Quebec, and 1987 represents the creation of the Med-Écho database, which we used to identify diagnoses of pregnancy complications. Sociodemographic data of the study women and of their mothers at their birth were extracted from the Demographic Events Registry. The success rate of record linkage between data from the Quebec Institute of Statistics for births (1976-1995) and Health Insured Individuals databases for deliveries (1987-2008) is estimated at 83\%. The loss of participants because of emigration is very low: between 1976 and 2008, 0.6\% women per year emigrated out of the province (Dominique André, Quebec Institute of Statistics: personal communication, 2012).

This study was approved by the Sainte-Justine University Hospital and Research Center Ethics Board, the Quebec Office of the Information and Privacy Commissioner, the Quebec Institute of Statistics and Régie de l'assurance maladie du Québec (Quebec Health Insurance Program).

\section{Outcome measures}

The main pregnancy complications studied were gestational diabetes, gestational hypertension, preeclampsia and eclampsia. We also extracted data on diagnoses of chronic hypertension, kidney diseases, and type 1 and type 2 diabetes.

Gestational age of the women was collected from the Demographic Events Registry, as noted on the declaration of birth. The weight percentile for gestational age was calculated using the Canadian reference charts by Arbuckle and colleagues $^{16,17}$ (1972 chart for women born during 1976-1979 and 1986 chart for those born during 1980-1995). A birth weight for gestational age below the 10th percentile or above the 90th percentile was considered small or large for gestational age. The medical diagnoses were categorized according to the coding system of the International Classification of Diseases, 9th revision, before Apr. 1, 2006, and the coding system of the International Statistical Classification of Diseases and Related Health Problems, 10th revision, from Apr. 1, 2006, onward.

\section{Statistical analysis}

Based on initial estimates, we were expecting 7000 eligible women born before 37 weeks' gestation and, of those, about $8 \%$ (560) born before 32 weeks. Our plan was to select 2 women born at term for each woman born before 37 weeks. Assuming that the risk of 1 or more pregnancy complications is $10 \%$ among women born at term, the planned sample size would provide at least $90 \%$ power to detect an absolute difference 
of $1.5 \%$ or more $(10.0 \%$ v. $11.5 \%$, odds ratio [OR] 1.2) between women born at term and those born at 32-36 weeks, or $4.5 \%$ or more $(10.0 \%$ v. $14.5 \%$, OR 1.5$)$ between women born at term and those born before 32 weeks using a 2 -sided test with an $\alpha$ level of 5\%. The potential efficiency gain induced by the frequency matching would slightly increase the power.

All analyses were performed using SPSS software, version 19.0. All reported $p$ values are 2 -sided. Gestational ages were divided into 3 categories: less than 32 weeks, 32-36 weeks and term (37-42 weeks). Preeclampsia and eclampsia were grouped together in all analyses. Group comparisons were performed on discrete variables using the $\chi^{2}$ test and on continuous variables using analysis of variance.

To establish whether a trend existed between gestational age at birth and the pregnancy complications studied, we performed normal logistic regressions using gestational age as a continuous variable and controlling for singleton versus twin status and year of birth of the participants. We performed normal logistic regressions using the 3 gestational age groups to obtain adjusted ORs and $95 \%$ confidence intervals (CIs). This analysis was done to distinguish the effect of preterm birth from the impact of confounding variables shown to be associated with increased risk of the pregnancy complications studied: small for gestational age and large for gestational age, ${ }^{8,10}$ multiple pregnancy, maternal age of 25 years or older ${ }^{18}$ diagnosis of chronic hypertension, type 1 or 2 diabetes, and kidney disease. ${ }^{19}$ The analyses were realized for (a) the risk of a pregnancy complication at least once during the study period (with the number of women affected as the unit of measurement and not the number of episodes; e.g., a woman with 3 pregnancies complicated by preeclampsia was included as 1 participant) and for (b) the risk of a pregnancy complication at the first live delivery. The former analysis allowed us to study all pregnancies of the participants over the whole study period,

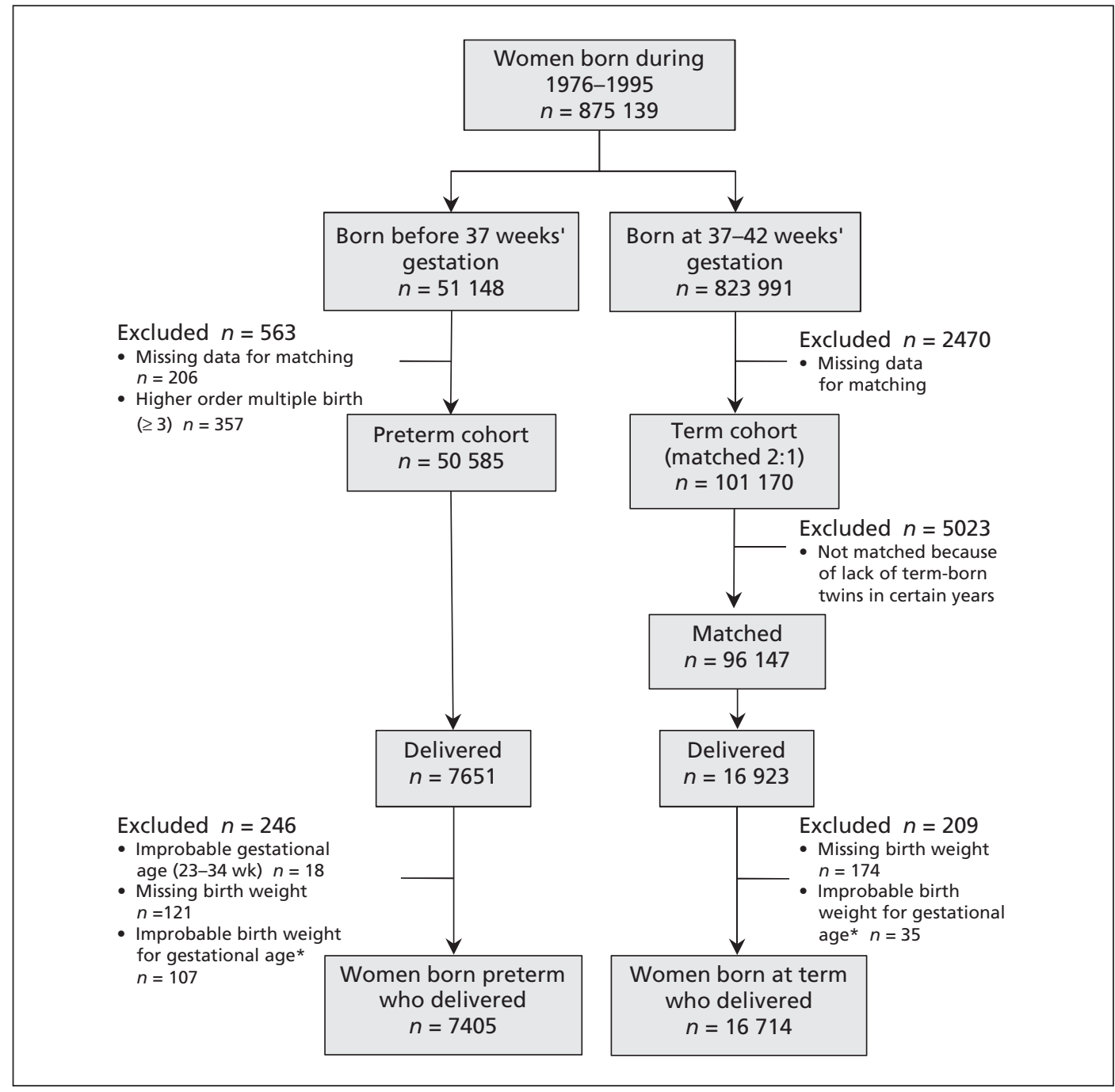

Figure 1: Establishment and follow-up of the study cohorts. *Based on criteria by Alexander and colleagues. ${ }^{20}$ 
whereas the latter analysis allowed us to control for confounding factors (e.g., pre-existing chronic hypertension), because the database does not date the diagnosis of the associated condition versus a specific pregnancy unless present at the first live delivery.

\section{Results}

\section{Study cohort}

The initial population of our study comprised all women born from 1976 to 1995 in the province of Quebec (Figure 1). After exclusion of records without complete data for matching and those born before 23 weeks' gestation or to multiplebirth $(\geq 3)$ pregnancies, 50585 women born preterm constituted the exposed cohort and 101170 women born at term were in the unexposed cohort. Considering that matching criteria were year of birth and singleton (v. twin) status, 5023 women born at term were not matched because of insufficient numbers of term-born twins. We identified women who had a live-birth delivery or a stillbirth between 1987 and 2008 and for whom data about their own birth weights and gestational ages were available and plausible. The final sample for analysis included 7405 women born preterm (554 born $<32$ weeks and 6851 born at 32-36 weeks) and 16714 women born at term. The birth and demographic characteristics of the women at their birth and at first live delivery are presented in Table 1.

Table 1: Characteristics of 7405 women born preterm and 16714 born at term, at the time of their birth and during the study period, by their gestational age

\begin{tabular}{|c|c|c|c|c|}
\hline \multirow[b]{2}{*}{ Characteristic } & \multicolumn{3}{|c|}{ Women's gestational age; no. (\%) of women* } & \multirow[b]{2}{*}{$p$ value } \\
\hline & $\begin{array}{l}<32 w k \\
n=554\end{array}$ & $\begin{array}{l}32-36 \mathrm{wk} \\
n=6851\end{array}$ & $\begin{array}{c}\text { Term, } 37-42 \mathrm{wk} \\
n=16714\end{array}$ & \\
\hline \multicolumn{5}{|l|}{ At birth } \\
\hline \multicolumn{5}{|l|}{ Mother's age, yr } \\
\hline$<18$ & $27(4.9)$ & $196(2.9)$ & $323(1.9)$ & $<0.001$ \\
\hline$\geq 25$ & $266(48.0)$ & $3661(53.4)$ & $9491(56.8)$ & $<0.001$ \\
\hline Mean \pm SD & $24.8 \pm 5.1$ & $25.3 \pm 4.8$ & $25.4 \pm 4.6$ & $<0.001$ \\
\hline Mother's education $<12 \mathrm{yr} t$ & $332(62.9)$ & $4001(62.0)$ & $9019(55.7)$ & $<0.001$ \\
\hline $\begin{array}{l}\text { Mother's first delivery (v. second or } \\
\text { more) }\end{array}$ & $251(45.3)$ & $3090(45.1)$ & $7101(42.5)$ & $<0.001$ \\
\hline Multiple birth & $57(10.3)$ & $513(7.5)$ & $1245(7.4)$ & 0.04 \\
\hline Gestational age, wk, median (IQR) & $30(29-31)$ & $36(34-36)$ & $40(39-40)$ & $<0.001$ \\
\hline Birth weight, g, mean \pm SD & $1500 \pm 504$ & $2482 \pm 543$ & $3199 \pm 490$ & $<0.001$ \\
\hline Small for gestational age & $48(8.7)$ & $1002(14.6)$ & 2498 (14.9) & $<0.001$ \\
\hline Born $<1980$ & $265(47.8)$ & $3519(51.4)$ & 9012 (53.9) & $<0.001$ \\
\hline \multicolumn{5}{|l|}{ During study period } \\
\hline Parity, no. of live births & & & & 0.14 \\
\hline 1 & $304(54.9)$ & $3476(50.7)$ & $8350(50.0)$ & \\
\hline 2 & $186(33.6)$ & 2527 (36.9) & $6187(37.0)$ & \\
\hline$\geq 3$ & $64(11.6)$ & $848(12.4)$ & $2177(13.0)$ & \\
\hline Stillbirth delivery & $6(1.1)$ & $36(0.5)$ & $89(0.5)$ & 0.22 \\
\hline At first live delivery & $n=517$ & $n=6405$ & $n=15978$ & \\
\hline \multicolumn{5}{|l|}{ Age, yr } \\
\hline$<18$ & $32(6.2)$ & $417(6.5)$ & $873(5.5)$ & 0.009 \\
\hline$\geq 25 \mathrm{yr}$ & $203(39.3)$ & $2456(38.3)$ & $6490(40.6)$ & 0.007 \\
\hline Mean \pm SD & $23.1 \pm 3.7$ & $23.1 \pm 3.8$ & $23.4 \pm 3.8$ & $<0.001$ \\
\hline Education $<12$ yrt & $212(44.6)$ & $2466(41.7)$ & $5340(36.0)$ & $<0.001$ \\
\hline Multiple birth & $<5 \ddagger$ & $26(0.4)$ & $86(0.5)$ & 0.12 \\
\hline \multicolumn{5}{|c|}{$\begin{array}{l}\text { Note: IQR = interquartile range, SD = standard deviation. } \\
\text { *Unless stated otherwise. } \\
\text { tData on education levels were available for } 23163(96 \%) \text { of the mothers at the time of the women's birth and for } 21209(88 \%) \text { of the women at the time of } \\
\text { their first delivery. } \\
\text { ¥Numbers less than } 5 \text { are not reported, to respect confidentiality. }\end{array}$} \\
\hline
\end{tabular}




\section{Outcomes}

Eclampsia diagnoses were grouped with those of preeclampsia in all analyses because of small numbers with eclampsia $(0.2 \%$ of women born preterm $[n=14]$ and $0.1 \%$ of women born at term $[n=22] ; p=0.28)$. The percentage of women with at least 1 pregnancy complication at least once during the study period increased significantly with decreasing gestational age at their own birth ( $p<0.001$ for trend; Figure 2). A similar correlation was observed when we analyzed data at first live delivery only ( $p<0.001$ for trend): the percentage of women with at least 1 pregnancy complication was $17.0 \%(n=88)$ among those born before 32 weeks' gestation, $10.8 \%(n=694)$ among those born at $32-36$ weeks' gestation and $9.6 \%(n=1535)$ among those born at term. The odds of a pregnancy complication at the first live delivery increased with decreasing gestational age categories at their own birth (after adjustment for small for gestational age, large for gestational age, singleton status, year of birth of the participant, chronic hypertension, kidney disease, type 1 or 2 diabetes, age 25 years or older, and multiplebirth pregnancy) (Table 2). Restricting the analysis to singleton women with a singleton first live delivery yielded similar results (Appendices 1 and 2, available at www.cmaj.ca/lookup/suppl /doi:10.1503/cmaj.120143/-/DC1).

Overall, the occurrence and odds of at least 1 pregnancy complication at least once during the study period were increased among women born small for gestational age (whether preterm or term) and for all preterm women after adjustment for being born from a multiple birth or large for gestational age, and for birth year of the participant (Table 3).

Precise socioeconomic status of participants is not included in the administrative databases except for education level, which was available for $88 \%$ of the women and for $96 \%$ of their mothers at the time of first live delivery. When we controlled for education level (for the subgroups for which the data were available), overall results were unchanged, and preterm birth remained significantly associated with increased risk of pregnancy complications at first live delivery, with the risk increasing with decreasing gestational age category.

The proportion of women with a diagnosis of chronic hypertension or type 2 diabetes over the study period was significantly increased in the cohort of preterm women. For chronic hypertension, the proportion was $1.4 \%(n=104)$ among preterm women versus $0.8 \%(n=140)$ among term women (OR [adjusted for singleton v. twin status, small for gestational age, large for gesta- tional age and year of birth] 1.70, 95\% CI 1.32 $2.20)$. For type 2 diabetes, the proportion was $0.5 \%(n=34)$ among preterm women versus $0.3 \%(n=45)$ among term women (adjusted OR $1.75,95 \%$ CI 1.12-2.73). The proportion of women with a diagnosis of chronic kidney disease was not different between women born preterm $(0.9 \%, n=66)$ and those born at term $(0.8 \%, n=138)($ OR $1.06,95 \%$ CI $0.79-1.42)$. Chronic hypertension, type 1 or 2 diabetes and small for gestational age were associated with a significantly increased risk of pregnancy complications (Appendix 1).

\section{Interpretation}

We found that the risk of pregnancy complications was significantly higher among women born preterm, independently of their own fetal growth. Furthermore, the increased risk of pregnancy complications associated with preterm birth represented a dose-response relation, with women of lowest gestational age being at the greatest risk. When divided into categories of gestational age, the risk of having at least 1 pregnancy complication nearly doubled among women born before 32 weeks' gestation versus those born at term. This study strengthens previous findings of increased risk of pregnancy complications in women born with low birth weights. ${ }^{6,8-12}$

An inverse relation between birth weight and risk of preeclampsia and of gestational diabetes

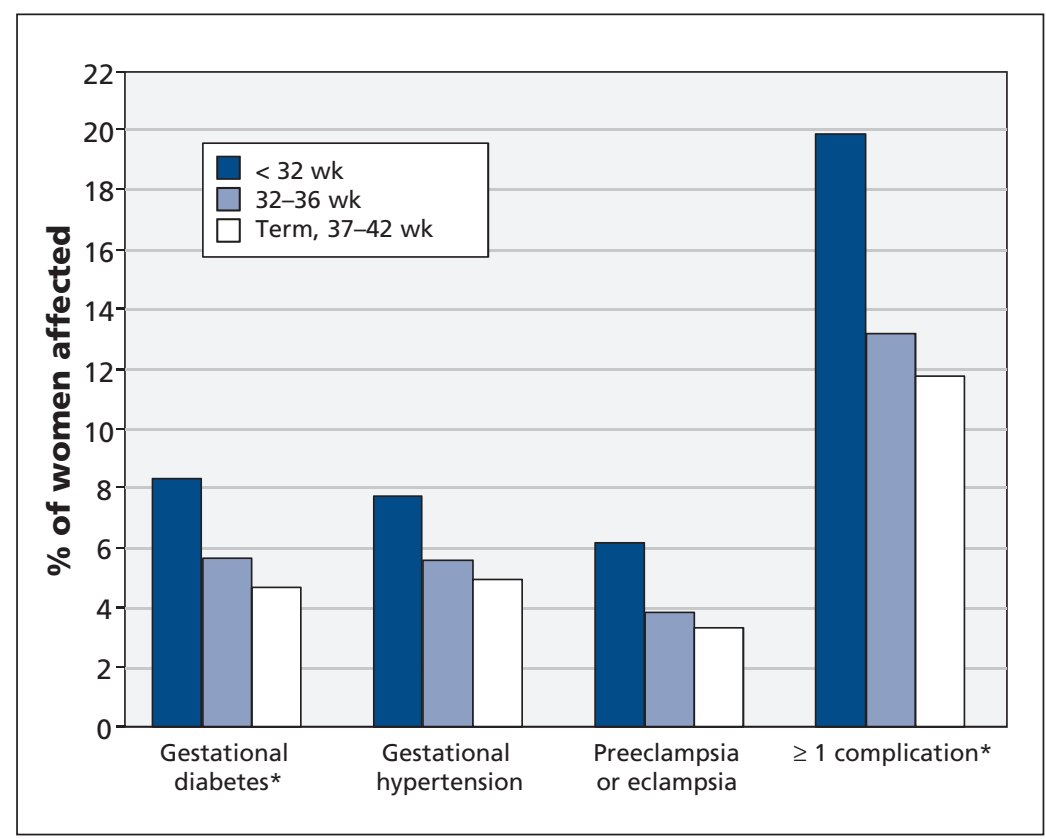

Figure 2: Percentage of women born preterm ( $<32 \mathrm{wk}$ or 32-36 wk) and term (37-42 wk) who had gestational diabetes, gestational hypertension, or preeclampsia or eclampsia, and percentage who had at least 1 of the pregnancy complications at least once. ${ }^{*} p<0.001$ for trend. 
has been shown in case-control and populationbased cohort studies. ${ }^{8,21,22}$ In a large populationbased cohort study, Zetterström and colleagues ${ }^{10}$ found an increased risk of preeclampsia among women born small for gestational age (v. appro-

\begin{tabular}{|c|c|}
\hline $\begin{array}{l}\text { Complication; gestational } \\
\text { age of women }\end{array}$ & $\begin{array}{l}\text { Adjusted OR* } \\
(95 \% \mathrm{CI})\end{array}$ \\
\hline \multicolumn{2}{|l|}{ Gestational diabetes } \\
\hline$<32 w k$ & $2.34(1.65-3.33)$ \\
\hline $32-36$ wk & $1.20(1.03-1.40)$ \\
\hline Term, 37-42 wk & 1.00 (ref) \\
\hline \multicolumn{2}{|l|}{ Gestational hypertension } \\
\hline$<32$ wk & $1.56(1.09-2.25)$ \\
\hline $32-36$ wk & $1.06(0.92-1.22)$ \\
\hline Term, 37-42 wk & 1.00 (ref) \\
\hline \multicolumn{2}{|l|}{ Preeclampsia or eclampsia } \\
\hline$<32$ wk & $1.79(1.19-2.69)$ \\
\hline $32-36$ wk & $1.23(1.04-1.44)$ \\
\hline Term, 37-42 wk & 1.00 (ref) \\
\hline \multicolumn{2}{|l|}{$\geq 1$ complication } \\
\hline$<32$ wk & $1.95(1.54-2.47)$ \\
\hline $32-36$ wk & $1.14(1.03-1.25)$ \\
\hline Term, 37-42 wk & 1.00 (ref) \\
\hline \multicolumn{2}{|c|}{$\begin{array}{l}\text { Note: } \mathrm{Cl}=\text { confidence interval, } \mathrm{OR}=\text { odds ratio, ref }= \\
\text { reference group. } \\
\text { *Adjusted for women's characteristics at the time of their } \\
\text { birth (small for gestational age, large for gestational age, } \\
\text { multiple birth, year of birth), chronic hypertension, type } 1 \\
\text { and } 2 \text { diabetes (except for gestational diabetes), kidney } \\
\text { disease, age } \geq 25 \text { years and multiple-birth pregnancy. }\end{array}$} \\
\hline
\end{tabular}

Table 3: Adjusted odds of $\geq 1$ pregnancy complication associated with gestational age of women and whether they were born small for gestational age

\begin{tabular}{|c|c|c|}
\hline $\begin{array}{l}\text { Gestational age of women; } \\
\text { size at birth }\end{array}$ & $\begin{array}{l}\text { No. }(\%) \text { of women } \\
\text { with } \geq 1 \text { complication }\end{array}$ & $\begin{array}{l}\text { Adjusted OR* } \\
\quad(95 \% \mathrm{Cl})\end{array}$ \\
\hline \multicolumn{3}{|l|}{$<32$ wk } \\
\hline SGA, $n=48$ & $11(22.9)$ & $2.42(1.23-4.76)$ \\
\hline Not SGA, $n=506$ & 99 (19.6) & $1.94(1.54-2.43)$ \\
\hline \multicolumn{3}{|l|}{ 32-36 wk } \\
\hline SGA, $n=1002$ & $158(15.8)$ & $1.48(1.23-1.77)$ \\
\hline Not SGA, $n=5849$ & $746(12.8)$ & $1.16(1.05-1.27)$ \\
\hline \multicolumn{3}{|l|}{ Term, 37-42 wk } \\
\hline SGA, $n=2498$ & $346(13.9)$ & $1.28(1.13-1.46)$ \\
\hline Not SGA, $n=14216$ & $1612(11.3)$ & 1.00 (ref) \\
\hline \multicolumn{3}{|c|}{$\begin{array}{l}\text { Note: } \mathrm{Cl}=\text { confidence interval, OR = odds ratio, ref = reference category, SGA = small for } \\
\text { gestational age. } \\
\text { *Adjusted for women's characteristics at the time of their birth: large for gestational age, } \\
\text { multiple birth, year of birth. }\end{array}$} \\
\hline
\end{tabular}

priate weight for gestational age). However, gestational age itself was not considered as an independent variable or not mentioned in most of the studies. Some reports included the concept of full-term versus preterm birth and suggested an increased risk of gestational hypertension, preeclampsia or gestational diabetes among women born preterm. ${ }^{6,11,12}$ These studies had a number of shortcomings. For example, in the studies by Klebanoff and coauthors ${ }^{12}$ and Pouta and colleagues, ${ }^{6}$ the participants were born between 1959 and 1966, and their average gestational age was not specified. It is thus possible to assume that the degree of prematurity was relatively mild, because these women survived at a time when neonatology in its current form did not exist. In the study by Innes and colleagues, ${ }^{11}$ the participants (born 1975-1983) were adolescents (12-20 years). Moreover, the primary aim was not to investigate the impact of preterm birth, and these observations were secondary analyses. Our study showed that preterm birth was a substantial risk factor for pregnancy complications, especially among women who were born before 32 weeks.

Before pregnancy, women born preterm may have undiagnosed risk factors for the studied pregnancy complications related to their preterm birth. Children and young adults born preterm have higher indexes of insulin resistance and glucose intolerance, and higher blood pressure values, ${ }^{2-4,23}$ which are risk factors for cardiometabolic diseases. Indeed, we found a significantly increased proportion of preterm women with diagnoses of chronic hypertension and type 2 diabetes; nevertheless, the impact of preterm birth remained significant after controlling for these conditions. Taken together, these data do not challenge the relation between low birth weight (often not distinguished from small for gestational age) and increased incidence of hypertension among adults, but they do support the postulate of an effect - probably major — of preterm birth itself on the development of conditions linked to metabolic syndrome in adults.

A potential hereditary component to the incidence of pregnancy complications could not be controlled for in our study because most of the participants were born before 1987, and hospital diagnoses of their mothers were not available. The possibility thus exists that the association between birth weight and prematurity and risk of pregnancy complications could be due to genetic factors that lead to premature birth and future pregnancy complications. Most studies regarding the developmental programming of pregnancy complications did not take into account pregnancy complications in the previous generation; 
those that did showed that the link between birth weight and preeclampsia and gestational diabetes was not modified after adjustment for preeclampsia and gestational diabetes in the previous generation. ${ }^{10,21}$ These studies thus suggest that pregnancy complications may have a developmental origin.

The reproduction rate of women born preterm has been reported to be lower than that of women born at term. ${ }^{24}$ In our study, the mothers of women born preterm were less educated and more often primiparous than the mothers of women born at term. A significantly smaller proportion of women born before 32 (v. 32-36 and 37-42) weeks' gestation were small for gestational age at birth. We cannot explain this observation, but one can postulate that the lower survival rates of very preterm, small-for-gestational-age infants, especially in the late 1970s and 1980s, could account for this difference. At the time of their first live delivery, a higher proportion of preterm women than of term women were less than 18 years old and had not reached 13 years of education, findings reported in other studies. ${ }^{25}$ Overall, the incidences of gestational diabetes, gestational hypertension, and preeclampsia or eclampsia among the women born at term were similar to the reported incidence in the Canadian or comparable populations..$^{19,26}$

The ways by which a perinatal environment can permanently alter cardiovascular and metabolic development and function, ultimately leading to chronic illnesses, are incompletely understood. Deleterious perinatal conditions (e.g., low birth weight and preterm birth) are associated with vascular dysfunction, arterial rigidity and microvascular changes; all could contribute to elevated blood pressure ${ }^{27-29}$ and to maladaptation to physiologic changes from pregnancy resulting in preeclampsia. ${ }^{30}$ Impaired $\beta$-cell development, as reported in models of deleterious perinatal conditions resulting in type 2 diabetes in adults, could prevent normal adaptation to pregnancy, during which insulin sensitivity decreases through changes in the insulin signalling pathway. ${ }^{31}$

\section{Strengths and limitations}

Our study addresses a number of shortcomings in previous studies of the relation between preterm birth and later pregnancy complications by evaluating the effect of preterm birth as a dose-response relation and independently of small weight for gestational age.

Certain limitations inherent in the use of administrative databanks remain, including the absence of information about confounding variables such as socioeconomic status, ethnicity, lifestyle factors, family history and obesity, which can affect the risk of pregnancy complications. The social determinants of small-for-gestational-age and preterm births overlap, which makes it difficult to disentangle risk factors for these outcomes. However, results were unchanged when education level (as a surrogate index of socioeconomic status) was taken into account in the analyses, which supports the concept that preterm birth is an independent risk factor of cardiometabolic pregnancy complications.

\section{Conclusion}

Our population-based study showed an increased risk of hypertensive and diabetic complications of pregnancy associated with preterm birth, especially among women born before 32 weeks' gestation. These findings were independent of low weight for gestational age. The impact of the patients' preterm birth on obstetric care should be taken into account in the care of pregnant patients, as well as in the allocation of resources in the health care system.

\section{References}

1. Osmond C, Barker DJ. Fetal, infant, and childhood growth are predictors of coronary heart disease, diabetes, and hypertension in adult men and women. Environ Health Perspect 2000;108 (Suppl 3):545-53.

2. Hofman PL, Regan F, Jackson WE, et al. Premature birth and later insulin resistance. N Engl J Med 2004;351:2179-86.

3. Hovi P, Andersson S, Eriksson JG, et al. Glucose regulation in young adults with very low birth weight. $N$ Engl J Med 2007; 356:2053-63.

4. Irving RJ, Belton NR, Elton RA, et al. Adult cardiovascular risk factors in premature babies. Lancet 2000;355:2135-6.

5. Aberg AE, Jonsson EK, Eskilsson I, et al. Predictive factors of developing diabetes mellitus in women with gestational diabetes. Acta Obstet Gynecol Scand 2002;81:11-6.

6. Pouta A, Hartikainen AL, Sovio U, et al. Manifestations of metabolic syndrome after hypertensive pregnancy. Hypertension 2004; 43:825-31.

7. Forest JC, Girouard J, Masse J, et al. Early occurrence of metabolic syndrome after hypertension in pregnancy. Obstet Gynecol 2005; 105:1373-80.

8. Claesson R, Aberg A, Marsal K. Abnormal fetal growth is associated with gestational diabetes mellitus later in life: populationbased register study. Acta Obstet Gynecol Scand 2007;86: 652-6.

9. Dempsey JC, Williams MA, Luthy DA, et al. Weight at birth and subsequent risk of preeclampsia as an adult. Am J Obstet Gynecol 2003;189:494-500.

10. Zetterström K, Lindeberg S, Haglund B, et al. Being born small for gestational age increases the risk of severe pre-eclampsia. BJOG 2007; 114:319-24.

11. Innes KE, Marshall JA, Byers TE, et al. A woman's own birth weight and gestational age predict her later risk of developing preeclampsia, a precursor of chronic disease. Epidemiology 1999; 10:153-60.

12. Klebanoff MA, Secher NJ, Mednick BR, et al. Maternal size at birth and the development of hypertension during pregnancy: a test of the Barker hypothesis. Arch Intern Med 1999;159:1607-12.

13. Births 2005 report. Ottawa $(\mathrm{ON})$ : Statistics Canada, Health Statistics Division; 2007. cat. no. 84F0210XIE.

14. Fellegi IP, Sunter A.B. A theory for record linkage. J Am Stat Assoc 1969;64:1183-210.

15. Fair M, Cyr M, Allen AC, et al. An assessment of the validity of a computer system for probabilistic record linkage of birth and infant death records in Canada. The Fetal and Infant Health Study Group. Chronic Dis Can 2000;21:8-13.

16. Arbuckle TE, Wilkins R, Sherman GJ. Birth weight percentiles by gestational age in Canada. Obstet Gynecol 1993;81:39-48.

17. Arbuckle TE, Sherman GJ. An analysis of birth weight by gestational age in Canada. CMAJ 1989;140:157-60, 165. 
18. Hollander MH, Paarlberg KM, Huisjes AJ. Gestational diabetes: a review of the current literature and guidelines. Obstet Gynecol Surv 2007;62:125-36

19. Magee LA, Helewa M, Moutquin JM, et al. Diagnosis, evaluation, and management of the hypertensive disorders of pregnancy. J Obstet Gynaecol Can 2008;30(Suppl):S1-48.

20. Alexander GR, Himes JH, Kaufman RB, et al. A United States national reference for fetal growth. Obstet Gynecol 1996;87:163-8.

21. Innes KE, Byers TE, Marshall JA, et al. Association of woman's own birth weight with subsequent risk for gestational diabetes. JAMA 2002;287:2534-41.

22. Wikström AK, Svensson T, Kieler H, et al. Recurrence of placental dysfunction disorders across generations. Am J Obstet Gyneco 2011;205:454-8

23. Vohr BR, Allan W, Katz KH, et al. Early predictors of hypertension in prematurely born adolescents. Acta Paediatr 2010;99:1812-8.

24. Swamy GK, Ostbye T, Skjaerven R. Association of preterm birth with long-term survival, reproduction, and next-generation preterm birth. JAMA 2008;299:1429-36.

25. Moster D, Lie RT, Markestad T. Long-term medical and social consequences of preterm birth. N Engl J Med 2008;359:262-73.

26. Stone CA, McLachlan KA, Halliday JL, et al. Gestational diabetes in Victoria in 1996: incidence, risk factors and outcomes. Med J Aust 2002;177:486-91.

27. Cheung YF, Wong KY, Lam BC, et al. Relation of arterial stiffness with gestational age and birth weight. Arch Dis Child 2004, 89:217-21

28. Mitchell P, Liew G, Rochtchina E, et al. Evidence of arteriolar narrowing in low-birth-weight children. Circulation 2008;118:518-24.

29. Martin H, Hu J, Gennser G, et al. Impaired endothelial function and increased carotid stiffness in 9-year-old children with low birthweight. Circulation 2000;102:2739-44.

30. Redman CW, Sargent IL. Latest advances in understanding preeclampsia. Science 2005;308:1592-4.

31. Reece EA, Leguizamon G, Wiznitzer A. Gestational diabetes: the need for a common ground. Lancet 2009;373:1789-97.
Affiliations: From the Departments of Paediatrics (Boivin, Lefebvre, Nuyt), Obstetrics and Gynaecology (Luo, Audibert) and Social and Preventive Medicine (Mâsse), Sainte-Justine University Hospital and Research Center, University of Montréal, Montréal, Que.; and the School of Psychology (Tessier), Laval University, Québec, Que.

Contributors: Ariane Boivin, Zhong-Cheng Luo, François Audibert, Francine Lefebvre, Réjean Tessier and Anne Monique Nuyt contributed to the conception and design of the study. Ariane Boivin and Anne Monique Nuyt collected the data and drafted the article. Ariane Boivin, Benoit Mâsse, Anne Monique Nuyt, Zhong-Cheng Luo and François Audibert contributed to the analysis and interpretation of data. All of the authors revised the article critically for important intellectual content and approved the final version of the manuscript submitted for publication.

Funding: This work was funded by a Canadian Institutes of Health Research (CIHR) operating grant (no. MCH-97584).

Acknowledgements: Ariane Boivin is supported by CIHR/ Fonds de recherche du Québec Quebec Training Network in Perinatal Research; Anne Monique Nuyt by a Fonds de la recherche en santé du Québec (FRSQ) Senior Scholar Award; Zhong-Cheng Luo by a CIHR New Investigator Award and an FRSQ Clinical Epidemiology Junior Scholar Award; and François Audibert by a CIHR New Investigator Award. The authors acknowledge the excellent work of research staff from Environnement pour la promotion de la santé et du bien-être platform and the Institut de la statistique du Québec (Quebec Institute of Statistics), in particular Isabelle Leroux and Luta Luse Basambombo; and Evelyne Rey for helpful suggestions. 